\title{
NIH Consensus Panel Recommends Expanding Access to and Improving Methadone Treatment Programs for Heroin Addiction
}

\author{
Public Information and Liaison Branch
}

National Institute on Drug Abuse, Rockville, Md., USA

A consensus panel convened by the National Institutes of Health (NIH) today strongly recommended a broader access to methadone maintenance treatment programs for people who are addicted to heroin or other opiate drugs and that the Federal and State regulations and other barriers impeding this access be eliminated.

Many people believe that opiate drug addictions are self-inflicted and efforts to treat them will inevitably fail. However, the 12-member panel concluded that opiate drug addictions are diseases of the brain and medical disorders that can indeed be effectively treated. Studies have shown that methadone maintenance treatment significantly lowers illicit opiate drug use, reduces illness and death from illicit opiate drug use, reduces crime and enhances social productivity.

Existing Federal and State regulations limit the ability of physicians and other health care professionals to provide methadone maintenance services for their patients. Additionally, these regulations require excessive paperwork and impose burdensome administrative and oversight costs. The panel recommended that these regulations be eliminated and that alternative means, such as accreditation, for improving the quality of methadone maintenance treatment programs be instituted.

'We know of no other area of medicine where the Federal Government intrudes so deeply and coercively into the practice of medicine', said panel chair Lewis L. Judd, MD, Chairman, Department of Psychiatry, University of California at San Diego School of Medicine. 'If extra levels of regulation were eliminated, many more physicians and pharmacies could prescribe and dispense methadone, making treatment available in many more locations than is now the case', Dr. Judd said.

In the USA, approximately 600,000 people are addicted to heroin. Opiate drug dependence typically begins in the teens and early to mid twenties, when young people are in their formative, early occupational, and reproductive years. Most do not receive treatment, and the financial costs of untreated heroin addiction to the individual, the family and to society are estimated to be approximately US\$ 20 billion per year. Most recent data indicate that there are about 115,000 patients in methadone maintenance treatment, many of whom require continuous treatment over a period of years and perhaps for life.

Many of the barriers to an effective use of methadone maintenance treatment are related to misperceptions and stigmas attached to heroin addiction, the people who are addicted, those who treat them and the settings in which services are provided.

The panel advocated vigorous and effective Federal and State leadership to educate the public that heroin addiction is a medical disorder that can be effectively treated with significant benefits for the individual and society.

Another barrier preventing broader access to methadone maintenance programs is the shortage of physicians and other health care providers who can competently treat heroin addiction. The panel recommended that all primary care medical specialists, psychiatrists, nurses, social workers, psychologists, physician assistants, and other health care professionals should be taught the principles of diagnosing and treating patients with heroin addiction.

The panel stressed the importance of providing substance abuse counseling, psychosocial therapies and other supportive services to enhance retention and successful outcomes in methadone maintenance treatment programs.

The panel urged that funding be sufficient to provide access to treatment for all who require it. They strongly recommended that legislators and regulators recognize that methadone maintenance treatment is both cost effective and compassionate and that benefits for treatment be part of public and private insurance programs.

\section{KARGER \\ Fax + 41613061234 \\ E-Mail karger@karger.ch}

(ㄱ) 1999 S. Karger AG, Basel www. karger.com
Accessible online at: http://BioMedNet.com/karger
Public Information Branch

National Institute on Drug Abuse - NIDA

5600 Fishers Lane

Rockville, MD 20857 (USA)

Tel. +1 301443 1124, Fax +1 3014437397 
Future research areas identified by the panel include studies to determine factors that lead to initial use of heroin, changes in the brain that result from repeated use of heroin, underlying processes of craving and differences between individuals who can stop heroin addiction and those who cannot. Additionally, the panel called for research to assess the prevalence of heroin addiction in the USA, for rigorous studies of the financial costs of heroin addiction, and for research on the factors that may affect positive treatment outcomes.

The panel issued their consensus statement following an extensive review of the existing medical literature and a series of presentations by heroin addiction research experts at a 3-day NIH Consensus Development Conference on Effective Medical Treatment of Heroin Addiction. This conference was sponsored by the NIH Office of Medical Applications of Research and the National Institute on Drug Abuse and was cosponsored by the NIH Office of Research on Women's Health.
The full consensus statement is available by calling 1-888-NIH CONSENSUS (1-888-644-2667) or by visiting the NIH Consensus Development Program web site at http://consensus.nih.gov.

The NIH Consensus Development Program was established in 1977 as a form of 'science court' to resolve in an unbiased manner controversial topics in medicine. To date, the NIH has conducted 107 such conferences addressing a wide range of controversial medical issues important to health care providers, patients and the general public. An average of six consensus conferences are held each year.

Note to Radio Editors

An audio report of the conference results are available from November 19-28, 1997, from the NIH Radio News Service by calling 1800 MED DIAL (1 800633 3425) or by visiting http://radiospace.com/nihhome.htm on the web. 